\title{
The Impact of Practice on Pedagogy: Reflections of Novice Evaluation Teachers
}

\author{
Jill Anne Chouinard and Ayesha S. Boyce \\ University of North Carolina at Greensboro
}

\begin{abstract}
In this practice note two novice evaluation teachers share their findings from research conducted with students who were enrolled in a theory and practicum course in evaluation. The study focused on understanding how and in what ways students navigate between the world of theory and the world of practice. The findings from this study subsequently led to a re-envisioning of the course offerings to provide a more nuanced transition between two dichotomized conceptualizations of evaluation (theory and practice), revised syllabi, and the addition of a third course. The implications of this research (and subsequent pedagogical revisions) raise important issues for evaluation teachers and practitioners, as we continue to debate the relationship between theory and practice in evaluation.
\end{abstract}

Keywords: evaluation teaching, novice evaluators, theory and practice

Résumé : Dans cette note de pratique, deux nouveaux professeurs dévaluation font part des résultats d'une étude effectuée auprès d'étudiants inscrits à un cours théorique et à un stage en évaluation. Létude visait à comprendre comment et de quelle façon les étudiants font la transition entre la théorie et la pratique. Les résultats de cette létude ont par la suite mené à une refonte de cours pour faciliter la transition entre des conceptualisations dichotomisées de lévaluation (théorie et pratique), une révision du curriculum et l'ajout d'un troisième cours. Cette recherche (les révisions pédagogiques qu'elle a entraînées) soulève des questions importantes pour les professeurs et les praticiens de lévaluation, alors que se poursuit le débat sur le lien entre la théorie et la pratique en évaluation.

Mots clés : enseignement de lévaluation, nouveaux évaluateurs, théorie et pratique

\section{INTRODUCTION}

In evaluation, the relationship between theory and practice remains a significant and ongoing concern. As an applied social science, program evaluation involves far more than the simple application of theory (Fitzpatrick, Christie, \& Mark, 2009), as the world of practice is often complex, dynamic, and indeterminate, not at all amenable to the direct application of theoretical knowledge (Polkinghorne, 1992; Schwandt, 2015). As evaluation is an interdisciplinary practice, there are a plethora

Corresponding author: Jill Anne Chouinard, Educational Research Methodology, School of Education, University of North Carolina at Greensboro, NC, USA; jill.chouinard@uncg.edu 
of competing theoretical perspectives available to assist evaluators in understanding the complexity of the social world and in rendering judgements about programs and policies. As new professors of evaluation who teach an evaluation theory course followed by a practicum course in evaluation, we have observed that our students experienced multiple challenges (and frustrations) as they attempted to navigate the relationship between theory and practice, between what they learned in the classroom and their experiences in the field. Simply put, our students wrestled with the fact that their theoretical understanding of evaluation could not provide them with a step-by-step guide to practice; they felt that the theory course did not adequately prepare them for the dynamic and sociopolitical nature of the evaluation context. As one of the students lamented, "There's no theory for when everything falls apart."

To help us better understand the experiences of our students and to help inform our teaching practice, we conducted a qualitative research study at the end of the academic year to further explore the perspectives of five graduate students who had been enrolled in both courses, and who volunteered to be part of our study as participants and coauthors (Chouinard et al., in press). Our research focused on understanding how and in what ways novice practitioners navigate between the world of theory and the "rough ground of practice" (Schwandt, 2003).

The introductory course provided students with an overview of the basic concepts, issues, theories, and models in evaluation. The goals of the course were to enable students to compare and contrast major theories of program evaluation, with a focus on determining which evaluation approach to use in a given context; developing an evaluation plan; identifying the various roles of the evaluator; understanding the social, historical, political, and cultural dynamics of an evaluation context; planning the collection of data; and establishing reporting processes.

The practicum course introduced students to the practical craft of program evaluation, particularly to the practices or methods that characterize evaluation in the field of education. Students planned and conducted a small-scale evaluation, with activities that included evaluation planning, data collection, analysis, interpretation of findings, and ongoing and final reporting processes. The objective of the course was to provide students with first-hand experience in conducting and managing a small-scale evaluation, applying basic data collection tools and using qualitative and quantitative data analysis, and completing both conventional and innovative reporting of results. As part of the practicum course, students were required to keep reflective journals where they were encouraged to record their evaluation experiences, reflections as novice evaluators, and share theoretical wrestlings, interpretive insights, and other challenges.

Our data for this research were based on (a) an analysis of the reflective journals students kept throughout the practicum course, (b) one-on-one interviews with each of the five students based on open-ended questions identified through our review of the literature and our reading of their reflective journals, and (c) a follow-up focus group with students to share our initial analysis and test out 
hunches and hypothesis. Our goal throughout was to deepen our understanding of their experiences as novice evaluators in the field, so as to ultimately inform our future evaluation curriculum and teaching practices.

Our study highlighted the three interconnected dimensions of practice that include context, theory, and personal and cultural biographies, all of which dynamically intersect in evaluation practice. These three dimensions shift the focus from a theory-practice binary to a focus on the sociocultural contexts and biographical forces that interact together in shaping evaluation practice. In what follows, we briefly share our key findings from this study and reflect on implications for our current teaching of both evaluation theory and practice.

\section{STUDY FINDINGS: DIMENSIONS OF PRACTICE}

The focus of our recent study was on understanding the relationship between theory and practice based on the perspectives and experiences of student evaluators, as they moved from the classroom to an engagement with practice. While there has been prior research related to the training of evaluators, the focus of this literature was not explicitly on understanding the relationship between theory and practice (Trevisan, 2004), but on specific aspects of training. For example, Hurley, Renger, and Brunk (2005) focused their research on teaching evaluation in the classroom and in the field; Alkin and Christie (2002) looked at the pedagogical benefits of role-play in training evaluators; Altschuld (1995) and others (Darabi, 2002; Morris, 1994) focused on the design of training courses; Lee, Wallace, and Alkin (2007) looked at a problembased learning approach to teaching evaluation; Kelly and Kaczynski (2008) explored the use of experiential learning with evaluation novices; Jewiss and Clark-Keefe (2007) examined the use of self-reflection for novices; and LevinRozalis and Rosenstein (2003) looked at the effects on mentoring on learning evaluation.

In our study, we privileged the concepts of theory and practice with novice evaluators to shed light on what remains a problematic and persistent dichotomy in evaluation, especially for those who are new to the field. In the social sciences, a tightly coupled relationship between theory and practice endures, as practice is thought to represent the technical expression or application of theory, an idea whose genesis can be traced to the conflation of theory in the natural sciences with theory in the social sciences (Flyvbjerg, 2001). However, theories in the social sciences must be distinguished from theories in the natural sciences, as they cannot provide evaluators with predictive certainty, but rather with what Schwandt (2014) refers to as "aids to the evaluation imagination" (p. 234). Our findings clearly show that the challenges evaluators confront in the field are complex, indeterminate, and highly specific to the sociopolitical and cultural context of the program and community. In other words, they cannot be solved through the simple application of the right theoretical principles. As one of the students described: 
There were certain aspects of theory that stuck with us but at the end of the day it goes out the window. It's kind of like scaffolding. If you're on a tightrope, it's the trampoline that's below you. If you get stuck you can rely on it but it may not get you from one end to the other.

As our students quickly learned, the program and evaluation context is far too dynamic and complex for any one theory to map on perfectly (van Manen, 1995).

A key finding in our study was that students' reification of theory, while likely related to their lack of evaluation expertise and confidence (Flyvbjerg, 2001), paradoxically also made it more challenging for them to let go of their expectation that theory alone could help them address the challenges of the context. Ironically, the messier the context, the greater the need students had for theory to ultimately prevail. The tension that students experienced between their understanding of theory and their actual field experience suggests that there is far more involved than the simple application of technical knowledge (Schwandt, 2003). Evaluation, as our students soon came to realize, is a sociopolitical process (Greene, 2000) that requires situational sophistication beyond the simple application of methodological rigour and skill. Our students' initial understanding of theory and practice, situated as it was in the intellectual tradition of the natural sciences (Carr \& Kemmis, 1986), ultimately could not provide the guidance nor the technical direction they required for an engagement with the exigencies of evaluation practice. As one of the students described, "we were kind of thinking that we would follow a little bit more of a roadmap, instead of building the plane while it's flying."

\section{IMPLICATION FOR PRACTICE}

As new teachers of evaluation, we primarily focused in our study on understanding how students navigate between the world of theory and the world of practice, as a way to inform our teaching practice. After conducting the study (Chouinard et al., in press), we spent the following year revising our course sequence and adapting our syllabi to better reflect our understanding of student engagement with theory and practice. At this point, we have re-envisioned the introductory evaluation course so that it aligns better with the evaluation practicum in the second semester, away from a view of evaluation demarcated by a theory-practice binary. We have also added a third, advanced course in evaluation that is focused almost exclusively on the study of evaluation theory. The goal in our redesign is to ensure that students have a basic understanding of the diversity of evaluation approaches and paradigmatic implications and methods of practice (e.g., evaluation design, logic models, frameworks) before they go out in the field to conduct an evaluation. The advanced theory course in evaluation is intended for students who wish to pursue careers in evaluation. In what follows, we describe our pedagogic modifications as we continue to reflect on how best to teach novice evaluators the theory and practice of evaluation.

Introductory Course. While students are introduced to some evaluation theory (e.g., different approaches and theorists), different paradigms, and 
methodological implications in this course, the predominant focus is on the technical aspects of evaluation (e.g., constructing a logic model, creating an evaluation plan and budget, developing evaluation questions, methods of data collection and analysis, approaches to reporting). Each class session provides students with hands-on activities related to specific technical skills, with two class sessions now devoted to constructing logic models. We also use case studies (see Patton \& Patrizi, 2005) in each class session to provide students with the opportunity to identify appropriate evaluation designs that are culturally and contextually appropriate; understand (and work through) the exigencies of program contexts; identify key stakeholders, evaluation purpose, and the role of the evaluator; develop strategies to address practical and method-based problems; and engage with diverse evaluation orientations. The case study approach also provides students with the opportunity to practice evaluation in a low-stakes setting, to make mistakes and adjustments, to practice reading diverse cultural contexts, to try on different evaluator roles, and to use different data collection methods and approaches based on identified evaluation questions. Our overall goal in this course is to ensure that students have ample opportunity to think through being evaluators and conducting evaluations across a diversity of program and community settings before they ever go out into the field. As Patton and Patrizi (2005) have stated, the use of the case study method enables novice evaluators to "bridge the gap between knowing and doing" (p. 98), a gap that our students have struggled to overcome.

Practicum Course. In this course, students transition from the safety of evaluation practice in the classroom setting to the "real world" of evaluation out in the field, from a case study model to an engagement with a real case. We aim to dissuade students from the expectation that they are methodological technicians whose job is merely to design and implement an evaluation regardless of multiple and very often competing contextual demands. While the study of case studies in the introductory course is not an engagement with a "real" evaluation, it nonetheless provides ample opportunity for students to learn about evaluation across multiple, diverse community and cultural program settings. In the practicum course, students are divided into small teams of two to three students, and together they select a program to evaluate among programs (and organizations) that we have preselected. Students work directly with their clients to design and conduct a small-scale evaluation, work that includes preparing an evaluation plan, collecting data, analyzing data, interpreting findings, and reporting. While the majority of class meetings are discussion-based, with dialogue about issues, problems, and solutions constituting the majority of the class session, the first few weeks are designed as workshops where students learn how to create an evaluation plan (evaluation design, logic model, evaluation framework, etc.). The overall goal of this course is to provide students with first-hand experience in conducting and managing a small-scale evaluation, applying basic data collection tools and using qualitative and quantitative data analysis, and completing both conventional and innovative reporting of results. 
Advanced Evaluation Theory Course. This new, advanced course provides students with the opportunity to critically examine a diversity of evaluation approaches and models from different evaluation roots (Alkin, 2013; Mertens \& Wilson, 2012). The course focuses on a range of evaluation approaches from the methods, use, values, and social justice branches of evaluation. This will provide students with the opportunity to discuss a diverse range of paradigms and ways of constructing knowledge, range of methods, values stances, evaluation use (and misuse), evaluation theorists, and methodological assumptions. Our goal in this course is to challenge students to think about the role of evaluation as promoting social betterment (Henry, 2000; Mark, Henry, \& Julnes, 2000) by thinking through the implications of their work as evaluators and researchers, and taking the time to explore the many (and varied) consequences of evaluation (and the role of evaluation) in society.

\section{CONCLUSION}

In this practice note, we shared the findings of a recent study we did with our students as they transitioned from the world of the classroom to active engagement with the dynamics of evaluation practice. Our goal in this study was to better understand how students navigate between the world of theory and the real world context of evaluation as a way to inform our teaching practice. As new evaluation teachers, we were interested in exploring the pedagogic implications of our research with students so that we could ultimately provide a more dynamic and focused learning experience for our students. Our research led to the subsequent redesign of our course offerings to provide a more nuanced transition between two dichotomized conceptualizations of evaluation-theory and practice. As we continue to reflect on our teaching and on our students' experiences inside and outside the classroom, we expect to continue to revise our teaching practices to reflect our own experiences inside these dynamic pedagogical environments.

\section{REFERENCES}

Alkin, M. C. (2013). Evaluation roots: A wider perspective of theorists' views and influences (2nd ed.). Thousand Oaks, CA: Sage.

Alkin, M. C., \& Christie, C. A. (2002). The use of role-play in teaching evaluation. American Journal of Evaluation, 23(2), 209-218. https://doi.org/10.1177/109821400202300210

Altschuld, J. W. (1995). Developing an evaluation program: Challenges in the teaching of evaluation. Evaluation and Program Planning, 18(3), 259-265. https://doi. org/10.1016/S0149-7189(95)00014-3

Carr, W., \& Kemmis, S. (1986). Becoming critical: Education, knowledge and action research. London: Routledge Farmer.

Chouinard, J. A., Boyce, A. S., Hicks, J., Jones, J., Long, J., Pitts, R., \& Stockdale, M. (in press). Navigating theory and practice through evaluation fieldwork: Experiences of novice evaluation practitioners. American Journal of Evaluation. 
Darabi, A. (2002). Teaching program evaluation: Using a systems approach. American Journal of Evaluation, 23(2), 219-228. https://doi.org/10.1177/109821400202300211

Fitzpatrick, J., Christie, C., \& Mark, M. M. (2009). Evaluation in action: Interviews with expert evaluators. Thousand Oaks, CA: Sage. https://doi.org/10.4135/ 9781412990288

Flyvbjerg, B. (2001). Making social science matter: Why social inquiry fails and how it can succeed again. Cambridge, UK: Cambridge University Press. https://doi.org/10.1017/ CBO9780511810503

Greene, J. C. (2000). Challenges in practicing deliberative democratic evaluation. New Directions for Evaluation, 85, 27-38.

Henry, G. T. (2000). Why not use? In V. J. Caracelli \& H. Preskill (Eds.), The expanding scope of evaluation use. New Directions for Evaluation, No. 88 (pp. 85-98). San Francisco, CA: Jossey-Bass.

Hurley, C., Renger, R., \& Brunk, B. (2005). Learning from a challenging fieldwork evaluation experience: Perspectives of a student and an instructor. American Journal of Evaluation, 26(4), 562-578. https://doi.org/10.1177/1098214005281323

Jewiss, J., \& Clark-Keefe, K. (2007). On a personal note: Practical pedagogical activities to foster the development of "reflective practitioners." American Journal of Evaluation, 28(3), 334-347. https://doi.org/10.1177/1098214007304130

Kelly, M. E., \& Kaczynski, D. (2008). Teaching evaluation from an experiential framework: Connecting theory and organizational development with grant making. American Journal of Evaluation, 29(4), 547-554. https://doi.org/10.1177/ 1098214008324181

Lee, J., Wallace, T. L., \& Alkin, M. (2007). Using problem-based learning to train evaluators. American Journal of Evaluation, 28(4), 536-545. https://doi.org/ $10.1177 / 1098214007305613$

Levin-Rozalis, M., \& Rosenstein, B. (2003). A mentoring approach to the one-year evaluation course. American Journal of Evaluation, 24(2), 245-259. https://doi. org/10.1177/109821400302400208

Mark, M. M., Henry, G., \& Julnes, J. (2000). Evaluation: An integrated framework for understanding, guiding, and improving public and non-profit policies and programs. San Francisco, CA: Jossey-Bass.

Mertens, D. M., \& Wilson, A. T. (2012). Program evaluation theory and practice: A comprehensive guide. New York, NY: Guilford Press.

Morris, M. (1994). The role of single evaluation courses in evaluation training. New Directions for Program Evaluation, 62(62), 51-59. https://doi.org/10.1002/ev.1676

Patton, M. Q., \& Patrizi, P. (Eds.) (2005). Teaching evaluation using the case method. New Directions for Evaluation, 105.

Polkinghorne, D. E. (1992). Postmodern epistemology of practice. In S. Kvale (Ed.), Psychology and postmodernism: Inquiries in social construction (pp. 146-165). Thousand Oaks, CA: Sage.

Schwandt, T. A. (2003). “Back to the rough ground!": Beyond theory to practice in evaluation. Evaluation, 9(3), 353-364. https://doi.org/10.1177/13563890030093008 
Schwandt, T. A. (2014). On the mutually informing relationship between practice and theory in evaluation. American Journal of Evaluation, 35(2), 231-236. https://doi. org/10.1177/1098214013503703

Schwandt, T. A. (2015). Evaluation foundations revisited: Cultivating a life of the mind for practice. Stanford, CA: Stanford University Press.

Trevisan, M. (2004). Practical training in evaluation: A review of the literature. American Journal of Evaluation, 25(2), 255-272. https://doi.org/10.1177/109821400402500212

van Manen, M. (1995). On the epistemology of reflective practice. Teachers and Teaching, 1(1), 33-50. https://doi.org/10.1080/1354060950010104

\section{AUTHOR INFORMATION}

Ayesha Boyce is an assistant professor within the Educational Research Methodology Department at the University of North Carolina at Greensboro (UNCG). Her research focuses on attending to value stances and issues related to diversity, equity, access, climate, cultural responsiveness, and restorative justice within evaluation-especially multisite, STEM, and contexts with historically marginalized populations. She also examines teaching, training, and novice learning in evaluation. Dr. Boyce has evaluated many programs funded by the National Science Foundation, the National Institutes of Health, Arizona Department of Education, Title VI, Illinois P-20 Council, and Spencer and Teagle foundations. She currently sits on the American Evaluation Association (AEA) Thought Leaders Committee for "An AEA Dialogue on Race and Class." From 2014 to 2016 she was the chair of the AEA STEM Education and Training TIG. She teaches classes in program evaluation and research methodology where she emphasizes good practice with mindful attentiveness to theoretical roots.

Jill Anne Chouinard is an assistant professor within the Educational Research Methodology Department at the University of North Carolina at Greensboro (UNCG). Her main interests are in cross-cultural/culturally responsive approaches to research and evaluation, participatory research and evaluation, and evaluation and public policy. Dr. Chouinard has extensive experience working on evaluations at the community level in the areas of education and training, social services, health, and organizational learning and change. Much of her evaluation work has been conducted in First Nations and Inuit communities, as well as in other culturally diverse community settings. She maintains a strong connection between her evaluation practice and her academic research. As such, her research and academic writing focuses on participatory approaches to evaluation in culturally diverse community settings, from both a national and an international perspective. 